\title{
Nota sobre a correção de Mimnermo por Sólon (26 G. e P.)
}

\author{
TEODORO RENNÓ ASSUNÇÃO \\ Faculdade de Letras - UFMG
}

RESUMO: Comentário à breve elegia (26 G. e P.) em que Sólon polidamente exorta Mimnermo a retirar seu verso que propōe que "o destino da morte atinja o que tem sessenta anos" (6W, 2) e o transforme no que propõe que "o destino da morte atinja o que tem oitenta anos." O comentário - evitando as conjecturas de ordem biográfica - tenta primeiro interpretar o dístico de Mimnermo a partir da visão da velhice manifesta em sua própria obra, e, em seguida e semelhantemente, a correção de Sólon a partir da concepção sobre as fases e o termo da vida presente no conjunto de seus poemas.

PALAVRAS-CHAVE: Termo da vida; Mimnermo; Sólon.

Adotando o texto da edição de B. Gentili e C. Prato (Gentili et Prato, 1979, p. 118) que no primeiro verso conserva o Käv dos códices e não incorpora, como M. L. West, a correção de Tiersch ( $\kappa \propto \grave{i}$ ) - propomos a seguir uma primeira leitura (ou seja: uma tradução) deste breve fragmento elegíaco de Sólon, visando não a uma recriação qualquer em português do ritmo composto por hexâmetros dactílicos e pentâmetros que formam os dísticos elegíacos, mas tão somente, mantida minimamente a unidade do verso, a uma correta apreensão do sentido que possa também facilitar o acompanhamento do comentário subseqüente. ${ }^{1}$
"se, mesmo agora, ainda me ouvires, retira isto -
e não me queiras mal, porque pensei melhor do que tu -
e recompõe, Filho-do-que-canta-claro, e canta assim:
"que o destino da morte atinja o que tem oitenta anos."”

Esta breve elegia (ou fragmento elegíaco) de Sólon ganha de imediato algum sentido, se ela for minimamente situada no contexto em que é citada, isto é: na biografia de

1 Este mesmo critério serve para as outras e provisórias traduções de Sólon e Mimnermo que apresento aqui. 
Sólon por Diỏgenes Laércio (Vidas, opiniões e sentenças dos filósofos mais ilustres). Pois ali ela é imediatamente antecedida pela citação do seguinte dístico elegíaco de Mimnermo (6W):

"que sem doenças e penosas preocupações

o destino da morte atinja o que tem sessenta anos."

Segundo Diógenes Laércio, “tendo Mimnermo escrito" este dístico, Sólon teria "repreendendo-o" ( $\dot{\varepsilon} \pi \imath \tau \iota \hat{\omega} v \tau \alpha \alpha \dot{\tau} \tau \hat{\omega})$ - dito sua breve elegia. Trata-se, portanto, de uma correção de um verso de Mimnermo que propõe a idade adequada para o fim da vida humana. Enquanto correção, o verso de Sólon não só se refere explicitamente ao verso de Mimnermo, como retoma literalmente sua fórmula ainda plenamente reconhecível, substituindo, porém, por um equivalente morfo-sintático, o termo decisivo que define a idade.

Antes, porém, de discutir o sentido desta modificação, eu gostaria de comentar os três versos que a introduzem. A primeira observação é a de que eles são dirigidos a alguém cujo patronímico em grego não só carrega um sentido significativo, como também pode ser reconhecido como sendo o de Mimnermo. Com efeito, segundo a Suda, "Mimnermo era chamado de $\Lambda \iota \gamma v \alpha \sigma \tau \tau \alpha ́ \delta \eta\rceil \zeta "$, nome próprio cujo sentido literal em grego é o de "Filho-do-que canta-

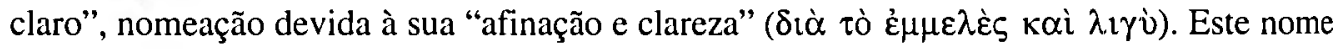
revela, mediada pela referência ao pai, uma qualidade positiva do poeta-cantor que está em consonância com o tom respeitoso do endereçamento. Wolfgang Schadewaldt caracterizou este tom como "maliciosa veneração" ("shalkhafte Ehrerbietung") (Schadewaldt, 1933, p. 284) ao mestre, enquanto Hermann Fränkel fala de "uma crítica polida" ("eine höfliche Kritik") (Fränkel, 1962, p. 250), sem que, no entanto, nenhum dos dois comentadores tenha se detido no conteúdo preciso do que, em princípio, não seria mais do que um endereçamento alargado e cerimonioso antecedendo - e criando a expectativa de - uma crítica concisa e contundente.

A oração subordinada que abre o poema - introduzindo uma possibilidade: "se, mesmo agora, ainda me ouvires" - poderia conter alguma desabusada ironia, se supuséssemos que, quando Sólon se dirige a Mimnermo, este último já teria ultrapassado os sessenta anos que ele mesmo sugere como limite para a vida (justificando, pois, a dúvida quanto à existência do poeta jônico no momento da enunciação: "se, mesmo agora, ainda..."). Não há, porém, no poema mesmo, nenhum índice seguro nem da idade então de Mimnermo, nem tampouco da de Sólon. E ainda que possa parecer também verossímil a hipótese de que Sólon, ao fazer esta proposição, tivesse mais do que sessenta anos ${ }^{2}$ e de que, sendo mais jovem do que Mimnermo, o poeta jônico tivesse então grandes chances de já estar morto, não há - como já foi dito - nenhuma evidência textual que possa servir de apoio a uma tal conjectura ${ }^{3}$. Assim como não há evidência textual - mas apenas externa sobre a suposta

2 Cf. W. Schadewaldt: "Solon war gewiss ein gut Stück über die Sechzig hinaus, als er diese Verse schrieb, und hätte nach Rechnung des Mimnermos längst tot zu sein." (Schadewaldt, 1933, p. 284).

3 Cf. M. L. West: "Mimnermus must have been young when he set sixty as a good age to die, but Solon was not necessarily old when he proposed eighty as a better idea. (...) There is nothing in the lines to indicate whether he is older or younger than Mimnermus." (West, 1974, p. 72 e 73). 
relação etária entre os dois poetas - que sustente a hipótese de que Sólon era bem mais jovem do que Mimnermo quando ele compôs esta elegia: segundo Szádeczky-Kardoss, "Sólon visitou Esmirna por volta de 610, quando ele tinha cerca de trinta anos, e aí encontrou Mimnermo, que estava então se aproximando de seu sexagésimo aniversário."4 Neste mesmo sentido vai a irônica e fantasiosa sugestão de que Sólon enviou este poema como presente de aniversário para Mimnermo quando este fez sessenta anos ${ }^{5}$. West considera, ao menos, que "Mimnermo devia estar vivo ainda", pois “(...) seria absurdo até mesmo fingir estar pedindo a um poeta para revisar sua obra e cantá-la diferentemente, se este poeta já estivesse no Hades." Mas, como admite o próprio West, "Sólon pode não ter pensado seu poema como uma genuína comunicação para os ouvidos de Mimnermo"” , ainda que ele tome esta forma ou, segundo a hipótese escritural de Schadewaldt, a de uma espécie de correspondência epistolar poética ${ }^{8}$. É indiferente, portanto, que, no momento da composição ou da recitação, Mimnermo estivesse de fato vivo ou morto, pois o que realmente interessa é a correção de sua já enunciada proposição sobre a idade adequada para a morte, isto é: a correção de um ponto de vista filosófico-prático, seja ela feita (real ou imaginariamente) pelo seu próprio autor ou por qualquer um que se identifique com sua "filosofia de vida".

Estamos apenas explicitando aqui, assumindo-a um pouco mais radicalmente do que West, a postura metodológica que considera o "eu" dos poemas como pessoa poética, não necessariamente coincidente com a pessoa real ou o indivíduo histórico. Segundo Wolfgang Rösler, esta interpretação do "eu" na lírica grega arcaica - em oposição àquela que considera o "eu" como pessoa real - é característica dos países de língua inglesa (o que, de algum modo, é comprovado pelo caso de West), enquanto a outra e oposta interpretação, a "realista" ou não-ficcional, seria própria dos países de língua alemã. A consulta a alguns clássicos da filologia alemã - como W. Schadewaldt, H. Fränkel e W. Jäger - tende a confirmar, no caso da interpretação deste poema, esta hipótese metodológica de W. Rösler ${ }^{9}$. No entanto, quando uma rápida tentativa de definição da elegia grega arcaica leva $\mathrm{H}$. Frănkel a explicitar

4 'Szádeczky-Kardoss' suggestion ('Wann lebte Mimnermos?' Egyet. philol. közl. 66, 1942, 80 f.) has been mentioned: Solon visited Smyrna c. 610 when he was about thirty years old and there met Mimnermus, who was then approaching his sixtieth birthday." (Allen, 1993, p. 66).

s "A less plausible suggestion (Steffen, V. Quaestiones lyricae, 1955, 44 ff.) is that Solon sent his poem as a gift to Mimnermus on the occasion of that sixtieth birthday." (Allen, 1993, p. 66).

6 "Mimnermus must be still alive (...) it would be absurd even to pretend to be asking a poet to revise his work and sing it differently if that poet was already in Hades." (West, 1974, p. 73).

7 "Solon may not have meant his poem as a genuine communication for Mimnermus' ears (...)." (West, 1974, p. 73).

8 "Und dieser Solon antwortet in einem Gedicht - wir kommen damit in eine Zeit und Welt, in der man sich gleichsam schon poetische Briefe schreibt - (...)." (Schadewaldt, 1989, p. 213).

9 E W. Jäger quem parece levar mais longe a identificação do "eu" deste poema com a pessoa real de Sólon, quando diz deste último: "A sua saudável energia ática e a sua indomável alegria de viver protegem-no contra o refinado cansaço melancólico que deseja colocar nos 60 anos o limite da existência, no intuito de se livrar das dores e moléstias de uma vida humana desamparada. A velhice não é para Sólon uma morte gradual e penosa. É o seu vigor juvenil inesgotável que permite à árvore da sua vida feliz e deleitosa dar todos os anos novas flores." (Jaeger, 1986, p. 128). 
seus pressupostos metodológicos na interpretação do "eu" destes poemas, estes pressupostos se mostram então longe de um acordo simples com a interpretação do "eu" como pessoa real, interpretação que, segundo W. Rösler, seria característica dos países de língua alemã. Eis o que diz H. Fränkel: "A elegia arcaica tem predominantemente o caráter da alocução pública ou semi-pública. Mesmo quando o poeta se dirige a princípio apenas a um único ouvinte, ele tem em vista o conjunto de todos os que estão em uma situação análoga; e quando ele fala de si mesmo, a própria pessoa lhe serve apenas de exemplo." "10. Alargando o quadro da definição, H. Fränkel já dissera pouco antes em uma nota que "o eu que sentencia na lírica arcaica é sempre pensado representativamente." "Coincidentemente, no quadro maior da lírica como técnica de comunicação oral, Bruno Gentili enumera os seguintes elementos característicos: "sentenças breves", "parataxe", "ausência de expressões de "caráter intelectual" e "o evitar qualquer uso idiossincrático - conseqüentemente, exibicionista e indiscreto - da primeira pessoa (...)". (Gentili, 1988, p. 39). Na nota de pé de página referida ao fim da sua breve definição da elegia grega arcaica, H. Fränkel vai, a partir das elegias de Arquíloco, sugerir também a ocasião preferencial para este tipo de discurso ritmado: “(...) o convívio dos homens ao beber era a ocasião normal para a instrução e reflexão poética."12

Estes pressupostos metodológicos de $\mathrm{H}$. Fränkel não o impedem de fazer coincidir o "eu" desta elegia e a pessoa real ou histórica de Sólon (como, de resto, já o fazia tacitamente Diógenes Laércio, o autor antigo que a cita), mas eles deixam claro que este "eu" interessa apenas na medida da possível universalidade de suas proposições. E - acrescentaríamos são estas proposições que, em seu conjunto, constituem por suas relações internas pertinentes a unidade dinâmica que chamamos "obra poética" e cujos indissociáveis estilo e visão de mundo passam então a ser reconhecidos pelo nome do autor que lhes é atribuído. A oposição excludente entre "pessoa poética" e "pessoa real" na interpretação do "eu" na elegia grega arcaica parece deixar, assim, de ser uma necessidade ou mesmo uma formulação adequada do fenômeno. E ainda que não descartando de uma vez por todas o uso possível de dados "biográficos" (cuja delicada relação com a "obra" é ainda mais problemática no caso de um autor lendário como Sólon), privilegiaremos na interpretação deste poema o modo como ele se deixa iluminar não só por sua relação com o poeta a que ele responde e modifica (isto é: Mimnermo), como também por suas relações com outros momentos tematicamente conexos da obra poética do seu próprio autor (isto é: Sólon).

Mas voltemos agora, após estes breves prolegômenos sobre o "eu" na elegia grega arcaica, ao comentário deste poema de Sólon, retomando sua abertura. O "retira isto" (ع́ $\xi \varepsilon \lambda \varepsilon$

10 "Die archaische Elegie hat vorwiegend den Charakter der öffentlichen oder halböffentlichen, Ansprache. Auch wenn der Dichter zunächst nur einen einzelnen anspricht, meint er doch die Gesamtheit aller die in ähnlicher Lage sind; und wenn er von sich selbst redet, dient ihm die eigene Person nur als Beispiel." (Fränkel, 1962, p. 170)

" "Das urteilende Ich in der archaischen Lyrik ist immer repräsentativ gemeint." (Fränkel, p. 69, nota 50).

12 “(...) das Zusammensein der Männer beim Trunk war die normale Gelegenheit für poetische Unterweisung und Reflexion." (Fränkel, 1962, p. 170). Cf. E. L. Bowie em "Early Greek Elegy, Symposium and Public Festival" para quem também o banquete ou simpósio era a ocasião preferencial - a única outra sendo o festival público - para a performance da elegia. 
tov̀ to) é tão direto e sem floreios quanto o "porque pensei melhor do que tu", mas ambos são também semelhantemente amenizados pelas orações antecedentes ("se me ouvires" e "não me queiras mal"), criando a tensão entre opostos - ou contraditório equilíbrio - já notada por W. Schadewaldt e H. Frankel. Mas o "porque pensei melhor do que tu" (ö $\tau$ $\sigma \varepsilon \hat{v}$

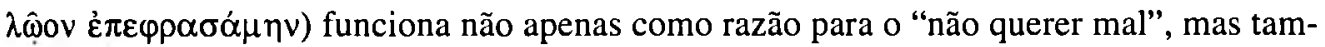
bém antecipadamente como motivo para o "refazer" (o verso) e "cantar de outra maneira". É como se um núcleo semântico fosse aqui o fundamento da recomposição poética de uma outra forma. Este núcleo está condensado no verbo $\dot{\varepsilon} \pi \varepsilon \varphi p \alpha \sigma \alpha \dot{\mu} \eta \eta$, aoristo do médio غ̇ $ı \varphi \rho \alpha ́ \zeta o \mu \alpha \iota$, que pode também querer dizer o "pensar em alguma coisa" ou "conceber, planejar" algo e o "perceber", "compreender" ou "reconhecer" algo ou alguém, sentidos que se articulam bem em torno do radical $\varphi \rho \alpha ́ \delta$-, cuja proximidade com o termo $\varphi \rho \eta ́ v$, sugerida etimologicamente por Pierre Chantraine (Chantraine, 1984, p. 1225), parece indicar que o pensamento ou percepção em questão é algo de ordem prática e que diz respeito à

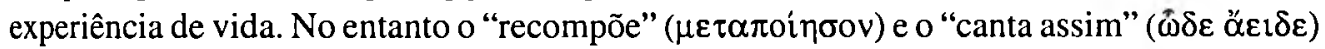
nos lembram que o registro desta discussão é o ritmo do canto composto por dísticos elegíacos, e que, na sua forma de resposta (real ou imaginária) a alguém que cantou antes, este canto parece pressupor a companhia ou o "estar com" que, juntamente com o vinho, compõem a ocasião do banquete ${ }^{13}$. E, como lembra $\mathrm{H}$. Fränkel, ao comentar a elegia $24 \mathrm{~W}$ de Sólon, o repertório típico da poesia de banquete é composto, entre outras, por referências à velhice, à doença e à morte ${ }^{14}$. Sabedoria e ritmo, prazer e reflexão se reúnem, portanto, indissociavelmente e sem falsas contradições tanto no veículo que é a elegia quanto no ambiente convivial para o "beber junto" (o banquete) que é sua ocasião.

\section{II}

Voltemos agora ao decisivo verso final desta breve elegia de Sólon. Antes de mais nada, caberia uma observação sobre sua tradução ou o que nela está implícito: o entendimento do texto grego. Para a maioria dos tradutores - Bowra (Bowra, 1938, p. 75), Frankel (Fränkel, 1962, p. 249-50), Jäger (Jaeger, 1986, p. 128), Adrados (Adrados, 1956, p. 199) e West (West, 1993, p. 79), a exceção neste grupo sendo Schadewaldt ("Achtzigjährig ereil jeden die Neige des Todes." Schadewaldt, 1933, p. 284) - haveria em elipse ou não explicitado um pronome da primeira pessoa do singular no acusativo $\mu \varepsilon$ : ("me") ${ }^{15}$ que seria qualificado

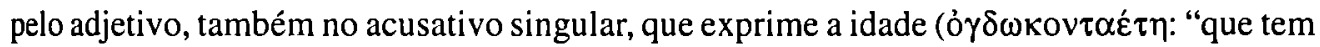
oitenta anos"), o que resultaria na seguinte tradução: "que o destino da morte me atinja com

${ }^{13}$ W. Schadewaldt parece também pressupor esta ocasião para esta elegia (mesmo que não a demonstre), quando se pergunta: "Sollten die Kumpane, wenn Solon es beim Symposium vortrug, vielleicht auch in ihm den Ton jener rüstigen Lebensgesinnung vernehmen (...)?” (Schadewaldt, 1933, p. 285).

14 "Wahrscheinlich haben wir es hier mit einem Stück Gelagepoesie zu tun, wozu auch der Hinweis auf Alter, Krankheit und Tod passt." (Frankel, 1962, p. 265).

is O que é explicitado em uma nota de Campbell: "Ǹgdwkontašth: acc. sing., sc. me, object of k...coi" (Campbell, 1967, p. 249). 
oitenta anos". Ora, o que está em elipse é apenas o acréscimo dos tradutores, uma vez que o texto grego prescinde tranqüilamente do pronome $\mu \varepsilon$ ("me") para constituir um sentido que, aliás, por ser mais declaradamente generalizável, é inteiramente adequado: "que o destino da morte atinja o que tem oitenta anos." A alternativa entre estas duas interpretações parece, porém, constituir não um problema real, mas apenas um sintoma de como em um tal tipo de proposição o pronome da primeira pessoa do singular nada retira à sua universalidade, pois, segundo os termos de $\mathrm{H}$. Fränkel, ele funciona antes como representante ou exemplo de "qualquer um".

Passemos agora ao comentário de suas relações com o verso citado - e, na citação, modificado - de Mimnermo. Hermann Frănkel comenta que é "como se apenas uma única palavra exigisse alteração, mas que, na realidade, o chão é retirado a uma das principais teses de Mimnermo."16 Se uma única palavra - "o que tem oitenta anos" por "o que tem sessenta anos" - basta para alterar todo o sentido da proposição, seria preciso então observar que o primeiro verso do dístico de Mimnermo, não citado por Sólon, deve (por isso mesmo) ser conservado na íntegra. Cabe, pois, antes de mais nada, nos perguntarmos pelo sentido do conjunto deste dístico de Mimnermo (6W):

"que sem doenças e penosas preocupações

o destino da morte atinja o que tem sessenta anos"

Antes do que colocar a irrespondível pergunta pela idade real do poeta (certamente jovem, segundo Szádeczky-Kardoss ou M. L. West) quando o compôs, tentaremos interpretálo à luz do conjunto dos outros fragmentos (ou poemas) elegíacos deste mesmo autor. As "doenças e penosas preocupações", que a morte evitaria ao indivíduo com sessenta anos ou mais, estão presentes (ainda que os termos não sejam exatamente os mesmos) em outras duas elegias de Mimnermo enquanto características ou elementos da velhice. Em Mimnermo $1 \mathrm{~W}$ o poeta diz: “(...) mas quando dolorosa sobrevier /a velhice, que torna igualmente feio até um homem belo, /sempre em torno do senso ( $\varphi p \varepsilon ́ v \alpha \varsigma$ ) o consomem ruins preocupações (...)." (5-7). O termo que traduzimos aqui por "preocupações" é $\mu \varepsilon ́ p \iota \mu v \alpha \iota$ e não $\mu \varepsilon \lambda \varepsilon \delta \omega v \varepsilon ́ \omega v$ que aparece em $6 \mathrm{~W}$, mas, apesar de os radicais serem distintos, a afinidade semântica entre os dois substantivos é estreita. Já o adjetivo $\alpha \rho \gamma \alpha \lambda \varepsilon ́ \omega v$ (genitivo plural) "penosas", que qualifica "preocupações" ( $\mu \varepsilon \lambda \varepsilon \delta \omega v \varepsilon ́ \omega v)$ em $6 \mathrm{~W}$, aparece em $1 \mathrm{~W}$ no acusativo neutro singu-

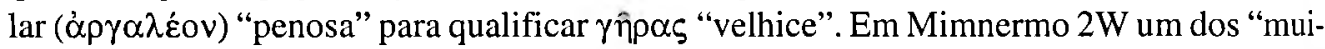
tos males que vêm a ser no ânimo" (11) daquele que ultrapassou "o termo da estação" (9) da juventude, ou seja: do velho, é precisamente "uma doença que destrói o ânimo" (vov̂бov

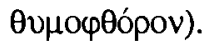

Se, portanto, "doenças e penosas preocupações" caracterizam em Mimnermo a velhice, sua proposição - expressa (no optativo) como desejo e não como exortação ao ato de um termo da vida aos sessenta anos poderia ser compreendida como o desejo de morrer antes da chegada da velhice. Mas o que autorizaria uma tal leitura senão, ainda uma vez, a

16 "Das klingt als sei nur ein einziges Wort der Änderung bedürftig; tatsächlich aber wird einer Hauptthese des Mimnermos der Boden entzogen.” (Frankel, 1962, p. 250). 
própria obra do poeta? Com efeito, em 1W Mimnermo diz: "Que eu esteja morto, quando isto não mais me importar: / secreto amor e doces dons e a cama (...)" (2-3), elementos que, no verso seguinte, são definidos como "as desejáveis flores da juventude" (4). E em 2W, se referindo de novo à juventude, Mimnermo diz: "Porém uma vez que for ultrapassado o termo da estação,/ imediatamente estar morto é melhor do que a vida". (9-10).

Um tal desejo - como evidencia já uma primeira leitura da obra de Mimnermo resulta não só de uma divisão da vida humana em duas grandes fases em tudo opostas: juventude e velhice, como também de uma caracterização inteiramente negativa da velhice, onde está ausente qualquer dimensão construtiva do tempo, como, por exemplo, em Homero, a sabedoria que resulta da experiência e que contrabalança um pouco a perda do vigor físico. Por outro lado, se a leitura que estamos propondo de Mimnermo 6W é adequada, o poeta estaria alargando o limite último da juventude até os sessenta anos e incluindo nela também a fase intermediária que chamamos "maturidade". "Jovem", nesta acepção lata (mas não guerreira) de Mimnermo, seria aquele que é capaz de gozar o amor. E, lembrandome de um Ulisses já quase cinquientão em seu reencontro com Penélope ${ }^{17}$, eu poderia me perguntar, como o fiz em "Juventude e velhice: Mimnermo": "É assim tão estranho que um homem com seus cinqüenta ou cinqüenta e cinco anos ainda seja plenamente capaz de gozar os dons de Afrodite?" (Assunção, 1998/1999, p. 162) .

\section{III}

Retomemos agora o verso final da elegia de Sólon (26 G. e P.) e imaginemos o dístico composto com o primeiro e não citado verso de Mimnermo conservado na íntegra:

"que sem doenças e penosas preocupações
o destino da morte atinja o que tem oitenta anos."

Para buscar o sentido desta proposição de Sólon o método que nos parece mais adequado é - como fizemos com Mimnermo - o de tentar interpretá-la a partir de uma leitura conjunta dos outros fragmentos de Sólon tematicamente conexos, evitando as inverificáveis conjecturas biográficas. Ernst Diehl (talvez impressionado pela chamada de Plutarco introduzindo a citação: "contradizendo Mimnermo quanto ao tempo de vida, ele [i.e.: Sólon] acrescentou") considerou o seguinte dístico (21W ou 27 G. e P.) como fazendo parte de uma mesma elegia cujo primeiro e maior fragmento seria aquele que estamos comentando (Diehl, 1936, p. 43):

"que a morte não me chegue sem ser chorada, mas aos amigos possa eu deixar, ao morrer, dores e gemidos."

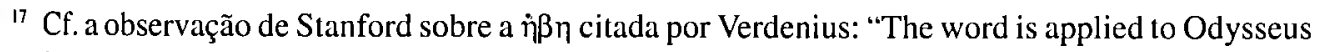
in 8,136 , though he must have been at least forty years old." (Verdenius, 1969, p. 346). 
Apesar da aparente coincidência temática: a morte, o que está sendo considerado neste dístico não é, como em Sólon 26 G. e P. (ou 20W), a idade adequada para o término da vida - ou seja: o indeterminado quando da possibilidade inevitável que define a temporalidade humana como finita -, mas o modo, já post-mortem, como os amigos reagirão a esta morte, o que - mesmo se em princípio dependendo da maneira como esta vida foi vivida diz respeito aos sobreviventes e escapa, enquanto tal, ao morto.

A morte enquanto termo da vida é um tema fundamental de outra elegia de Sólon (27W ou 19D): a que apresenta concisamente a vida do homem em dez períodos ou microfases de sete anos. O último setênio, com que o poema é concluído, é descrito assim no último dístico:

"E se alguém chegar ao décimo, terminando-o segundo a medida, que - não estando fora de hora - possa ter seu destino de morte."

O que chama primeiramente a atenção é a diferença de dez anos em relação à elegia que corrige Mimnermo: no poema das idades o termo de vida proposto é - como na fala de Sólon a Creso no livro I (32) de Heródoto - setenta anos, enquanto naquela é oitenta anos. Hermann Fränkel tentou minimizar ou resolver a discrepância dizendo que naquela "um desejo pessoal é expresso, enquanto aqui o caso normal é constatado" ou ainda que naquela "a intenção polêmica levou a que a diferença entre as duas concepções de vida fosse o máximo possível alargada." ${ }^{18}$ Não me parece possível minimizar esta discrepância por nenhuma explicação de ordem retórica. E continua sendo impossível responder a conjecturas de ordem biográfica tais como: "teria Sólon, quando compôs a correção a Mimnermo, necessariamente mais de setenta anos ou, ao contrário, como supõem Szádeczky-Kardoss e West, seria ele jovem e desconhecedor dos males da velhice?" Podemos, no entanto, apesar da insuprimível diferença, extrair da exposição mais circunstanciada do poema das idades uma ordem análoga de considerações que pode nos ajudar a compreender melhor a correção de Sólon a Mimnermo. A noção que ordena a descrição da vida do homem como um natural e gradual desenvolvimento é também a da finitude da temporalidade. Pois, como sugere H. Steinhagen, “(...) só se pode falar propriamente de um desenvolvimento, quando o processo tem começo, apogeu e fim (...)"19, sendo a morte o que dá ao desenvolvimento o seu sentido. Este "desenvolvimento" inclui, portanto, como fase necessária e terminal, o declínio representado pela velhice. Ela começa após o ápice ( $\dot{\alpha} \kappa \mu \eta \dot{\eta})$ espiritual do sétimo e do oitavo setênios - quando o homem "é muito excelente em bom-senso e discurso" (13) - e é descrita assim:

18 "Der scheinbare Widerspruch zu Fgt. 22, 4 klärt sich dahin auf, dass dort ein persönlicher Wunsch ausgesprochen wird, während hier der Normalfall festgestellt ist; und dass dort die polemische Absicht Anlass gab, den Unterschied der beiden Lebensauffassungen so gross wie möglich zu machen." (Fränkel, 1962, p. 266). Ver também o comentário de Bowra: "With Mimnermus he was pressing a special point and allowed himself some pardonable exaggeration." (Bowra, 1938, p. 101).

19 "Denn nur, wenn ein Vorgang Anfang, Höhepunkt und Ende hat, kann man eigentlich von einer Entwicklung sprechen (...)." (Steinhagen, 1966, p. 604). 
"No nono, ainda tem capacidade, mas mais fracos para a grande excelência o discurso e a sabedoria."

É certo que o conteúdo de vida do último setênio (63-70 anos) nem chega a ser descrito, enquanto o penúltimo (56-63 anos) é caracterizado por uma negatividade relativa: a maior fraqueza (em relação aos dois setênios anteriores que constituem o ápice espiritual) do discurso e da sabedoria. Mas, diferentemente do que ocorre em Mimnermo, a velhice não representa uma negatividade total, insistentemente deplorada e temida e que justificaria, portanto, o desejo de não mais viver depois dos cinqüenta e seis (ou sessenta) anos. Alargando o prazo de vida até os oitenta anos, é como se Sólon considerasse os vinte anos que vão dos sessenta aos oitenta (e aos quais Mimnermo prefere a morte) como plenamente dignos de serem vividos e - se supomos o primeiro verso de Mimnermo conservado na íntegra - como possíveis "sem doenças e penosas preocupações", ainda que "mais fracos para a grande excelência o discurso e a sabedoria", o que evidentemente não quer dizer que eles - discurso e sabedoria - tenham desaparecido ou se deteriorado totalmente.

É surpreendente, porém. o que diz um outro dístico elegíaco de Sólon (26W), citado por Plutarco como prova do "excedente de ócio" ( $\sigma \chi 0 \lambda \hat{\eta} \varsigma \pi \varepsilon \rho t o v \sigma i \alpha v)$ de que dispunha Sólon em sua velhice, época em que ele já havia se retirado da vida pública:

\section{"mas agora me são caras as obras da-nascida-em-Chipre e de Dioniso e das Musas, (obras) que proporcionam alegrias aos homens."}

As presenças divinizadas do canto (as Musas), do vinho (Dioniso) e do amor (Afrodite, a nascida em Chipre) configuram precisamente o espaço do banquete e indicam ainda uma vez a alta importância atribuída por Sólon a estes "prazeres" ou "alegrias" civilizados

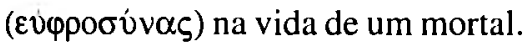

Mas é o verso (um pentâmetro) citado em primeiro lugar por Plutarco, como teste-

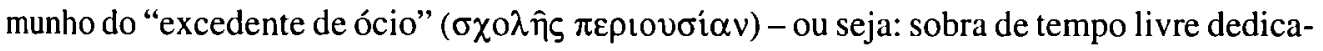
do ao estudo (ou à contemplação) - de que Sólon dispunha na velhice, o que constituirá a peça decisiva na interpretação da correção de Sólon a Mimnermo. ${ }^{20}$ Este verso proverbial de Sólon ( 18 W ou 28 G. e P.) diz o seguinte:

"e envelheço aprendendo sempre muitas coisas."

É curioso que o Catão de Cícero no De senectude, após parafrasear este verso, acrescentasse como exemplo ele próprio que, já velho, aprendera as "letras gregas". ${ }^{21}$ Mas Sólon, na concisão proverbial deste verso, não dá exemplos e não restringe, deste modo, a genera-

20 "Es mag die von Mimnermos so programmatisch Grenze von 60 Jahren (Mim. Fr. 6) überschritten und - aus der eigenen Erfahrung, dem 'Weiterlernen' veranlasst - den 60 jahren seinen eigenen Wunsch entgegengesetzt haben (fr. 22, 4)." (Preisshofen, 1977, p. 85).

21 "Solonem versibus gloriantem videmus qui se cotidie aliquid addiscentem dicit senem fieri et ego feci, qui litteras Graecas senex didici (...)." (Martina, 1968, p. 324). 
lidade da proposição. Pois não é tanto o número ou a multiplicidade de objetos do aprendizado - que no neutro plural ( $\pi \circ \lambda \lambda \dot{\alpha}$ ) permanece indefinido - o que nos parece estar em foco aqui, mas a transformação contínua - indicada pelos sufixos interativos ( $\sigma \kappa-)$ de $\gamma \eta p \alpha ́ \sigma \kappa \omega$ ("envelheço") e $\delta 1 \delta \alpha \sigma \kappa o ́ \mu \varepsilon v o \varsigma$ ("aprendendo") - tanto do sujeito quanto do objeto de um aprendizado cujo campo é a experiência de vida do homem. Em vez do conselho sabido vindo da experiência de uma vez por todas adquirida, a constatação aberta daquilo que possibilita sua formação: a capacidade de se deixar ensinar. ${ }^{22}$ Caberia agora - antes de voltarmos à correção a Mimnermo - investigar na obra poética de Sólon o fundamento temporal e ontológico de um tal processo.

Que a aprendizagem é constitutiva da existência humana, é algo não só implícito no "desenvolvimento" gradual do homem apresentado no poema das idades, como também explicitado na elegia às Musas ( $13 \mathrm{~W}$ ) quando da crítica - que é um tópos na poesia grega arcaica - às ilusões ou "esperanças vazias". Neste contexto negativo Sólon diz o seguinte (34-6):

"cada um tem, ele próprio, sua expectativa de as coisas correrem bem, antes de sofrer algo; e então ele se lamenta; mas até este momento nos deleitamos estuporados com esperanças vazias."

Tal proposição nos lembra a contingência fundamental que para o Sólon de Heródoto $(\mathrm{I}, 32)$ - no seu diálogo com Creso - justifica a necessidade de se conhecer o fim da vida de um homem para poder defini-lo como "feliz". "Pois - como diz este Sólon herodótico - em um longo tempo de vida é possível ver muitas coisas que alguém não desejaria ver, e também sofrer muitas coisas (que alguém não desejaria sofrer)." ${ }^{23}$ (Hérodote, 1946, p. 49-50). A possibilidade de sofrer algo que destrua nossas expectativas otimistas estaria, portanto, sempre presente e expressaria, em um modo negativo, a inultrapassável indeterminação do futuro. ${ }^{24}$ Sólon a reafirma em uma outra passagem da elegia às Musas (13W) que, voltada para o fazer humano, diz o seguinte (65-66):

"em todas as ações existe risco, e ninguém sabe, começada uma empresa, como ela irá resultar."

22 "Dass nicht die Fähigkeit des erfahrenen Rates, sondern die Voraussetzung dafür, die Fähigkeit, immer weiter zu lernen und aufzunehmen, hervorgehoben wird, zeigt den durchdringenden Blick des alternden Solon, der damit ein deutliches Zeugnis gegen den Zwang der Alterrigidität ablegt." (Preisshofen, 1977, p. 85).

${ }^{23}$ Adoto aqui o texto grego da edição Belles Lettres, mas a tradução é minha.

${ }^{24}$ Em meu "Breve comentário sobre o poema das idades de Sólon" já observara que o terceiro verso do poema ("E quando o deus leva a termo os outros sete anos") nos lembra que o processo gradual de maturação físico-moral “(...) pode eventualmente não ser levado a termo e ser interrompido (antes mesmo que cada período chegue a seu fim) por um acidente, evento ou doença qualquer que escape ao controle do indivíduo - o que, enquanto contingência decisiva e misteriosa, na linguagem religiosa arcaica é concebido como atuação da divindade: theós." (Assunção, 2001, p. 426). 
É, pois, o caráter fundamentalmente aberto (ou indeterminado) da existência humana e não a multiplicidade inesgotável de entes no mundo - o que faz com que um velho, mesmo tendo a maior parte de sua vida já definida, possa ser surpreendido e possa (ou deva) também estar sempre aprendendo alguma coisa nova. Ainda que o ápice físico e o espiritual da vida já tenham passado, um velho - desde que com um mínimo de saúde (ou seja: "sem doenças e penosas preocupações") - ainda dispõe de uma dose (cada vez menor, mas indeterminável) de futuro cujo valor é, em princípio, tão imponderável quanto o de qualquer outro segmento de sua vida.

\section{Referências Bibliográficas}

ADRADOS, Francisco R. (texto y traducción). Líricos griegos: elegíacos y yambógrafos arcaicos vol.1. Barcelona: Alma Mater, 1956.

ALLEN, Archibald (Text and Commentary). The Fragments of Mimnermus. Palingenesia Band 44. Stuttgart: Franz Steiner Verlag, 1993.

ASSUNÇÃO, Teodoro R. Breve comentário sobre o poema das idades de Sólon. In: O novo milênio: interfaces lingüísticas e literárias (orgs. Mendes, E. A. M., Oliveira, P. M. e Benn-Ibler V.). Belo Horizonte: FALE-UFMG, 2001, p. 423-32.

ASSUNÇÃO, Teodoro R. Juventude e velhice: Mimnermo. KLEOS: Revista de Filosofia Antiga, Rio de Janeiro, n. 2/3, p. 158-71, 1998/1999.

BOWIE, E. L. Early Greek Elegy, Symposium and Public Festival. Journal of Hellenic Studies, London, n. 106, p. 13-35, 1986.

BOWRA, Cecil M. Early Greek Elegists. Cambridge, Mass.: Harvard University Press, 1938.

CHANTRAINE, Pierre. Dictionnaire étymologique de la langue grecque vols. 3-4. Paris: Klincksieck, 1984.

CAMPBELL, David A. Greek Lyric Poetry. New York: St. Martin's Press, 1967.

DIEHL, Ernst (Ed.). Anthologia Lyrica Graeca vol. I. Leipzig: Teubner, 1936.

FRÄNKEL, Hermann. Dichtung und Philosophie des frühen Griechentums. 2. Aufl. München: C. H. Beck, 1962.

GENTILI, Bruno et PRATO, Carolus (Eds.). Poetarum Elegiacorum Testimonia et Fragmenta-Pars Prior. Leipzig: BSB B. G. Teubner Verlagsgesellschaft, 1979.

GENTILI, Bruno. Poetry and Its Public in Ancient Greece (transl. Thomas Cole). Baltimore: The Johns Hopkins University Press, 1988.

HERODOTE, Histoires - livre I (texte établi et traduit par Ph.-E. Legrand). Paris: Les Belles Lettres, 1946.

JAEGER, Werner. Paidéia: a formação do homem grego (Trad. Artur M. Parreira). São Paulo: Martins Fontes, 1986.

MARTINA, Antonius (Ed.). Solon: Testimonia veterum. Roma: Edizioni dell'Ateneo, 1968. 
PREISSHOFEN, Felix. Untersuchungen zur Darstellung des Greisenalters in der frühgriechischen Dichtung. Hermes - Einzelschriften - Héft 34. Wiesbaden: Franz Steiner Verlag, 1977.

RÖSLER, Wolfgang. Persona reale o persona poetica? L'interpretazione dell' 'io' nella lírica greca arcaica. Quaderni Urbinati di Cultura Classica, Urbino, n. 48, p. 131-45, 1985.

VERDENIUS, W. J. Tyrtaeus 6-7 D: A Commentary. Mnemosyne, Utrecht, n. 22, p. 337$55,1969$.

SCHADEWALDT, Wolfgang. Die frühgriechische Lyrik: Tübinger Vorlesungen Band 3. Frankfurt am Main: Suhrkamp Verlag, 1989.

SCHADEWALDT, Wolfgang. Lebenszeit und Greisenalter im frühen Griechentum. Die Antike, Berlin, n. 9, p. 282-302, 1933.

STEINHAGEN, Harald. Solons Lebensalter-Elegie (Fr. 19D). Eine Interpretation. Studium Generale, Heidelberg, n. 19, Heft 10, p. 599-606, 1966.

WEST, Martin L. (Ed.). Delectus ex Iambis et Elegis Graecis. Oxford: Oxford University Press, 1980.

WEST, Martin L. (transl.). Greek Lyric Poetry. Oxford: Oxford University Press, 1993.

WEST, Martin L. Studies in Greek Elegy and Iambus. New York: Walter de Gruyter, 1974.

ASSUNÇÃO, Teodoro Rennó. Note sur la correction de Mimnerme par Solon (26 G. et P.) Classica, São Paulo, 15/16, p. 51-62, 2002/2003.

RÉSUMÉ: Commentaire sur la brève élégie ( 26 G. e P.) dans laquelle Solon exhorte poliment Mimnerme à retirer le vers qui propose "que le destin de la mort atteigne celui qui a soixante ans" $(6 \mathrm{~W}, 2)$ et le transforme en cet autre qui propose "que le destin de la mort atteigne celui qui a quatre-vingt ans." Ce commentaire - en évitant les conjectures d'ordre biographique - essaie d'abord d'interpréter le distique de Mimnerme à partir de la vision de la vieillesse exprimée dans sa propre œuvre, et, ensuite et semblablement, la correction de Solon à partir de la conception sur les âges et le terme de la vie enoncée dans l'ensemble de ses poèmes.

MOTS-CLÉS: Terme de la vie; Mimnerme; Solon. 